\title{
Research on Exercise Intervention on Health Promotion of the Elderly
}

\author{
Jing Bao \\ Department of Physical Education \\ Northwest University \\ Xi'an, China 710127
}

\author{
Shanping Chen \\ Sports Center \\ Xi'an Jiaotong University \\ Xi'an, China 710049
}

\author{
Liping Liu \\ Sports Center \\ Xi'an Jiaotong University \\ Xi'an, China 710049
}

\begin{abstract}
The aging population has become an important social issue facing all countries in the world. How to increase the physical health status of the elderly through economic and effective means of exercise so that early prevent chronic diseases in the elderly. While improving the body function and life quality of elderly, reducing social financial burdens and medical expenditure has become a hot issue in the academic community. In this study, a literature review was used to analyze relevant studies on the effects of exercise interventions on the health of the elderly at home and abroad, review the research history of the effects of exercise interventions on the health of the elderly, and explain the deficiencies of current research and reflections on future research and development.
\end{abstract} health

Keywords-aging population; exercise interventions; elderly

\section{INTRODUCTION}

Nowadays, he aging population has become an important social issue facing all countries in the world. It is predicted in the Blue Book on Aging: Development Report of China's Aging Industry (2014 edition): From the year 2022 to 2030, aging population in China will enter into a rapid development stage. Till 2050, China's population over the age of 65 will account for $31.3 \%$ of the total population [1]. Issue of aging is a common one that everyone will eventually face, "If we cannot face and solve the problems of the current elderly, we will face more terrible dilemmas in the future" [2]. The World Health Organization puts forward that healthy aging is not only reflected in the extension of the lives of the elderly, but more importantly, the improvement of the life quality. [3]. While the primary prerequisite for ensuring the life quality of the elderly is health.

Since China entered an aging society, the number of elderly people has increased dramatically. Due to imperfections in medical and social security systems, health problems caused by diseases have become a major factor affecting the life quality of the elderly. Judging from the current related researches, exercise intervention has great advantages in promoting the elderly to establish a good sports lifestyle, and is an effective means to improve the physical and mental health of the elderly in various countries. This study will collate and analyze the intervention policies and intervention patterns of exercise on health promotion for the elderly and health exercise for the elderly (physical health, mental health and social adaptability) at home and abroad in order to provide evidence and reference for future related research.

\section{RELATED RESEARCH ON INTERVENTION OF EXERCISE FOR HEALTH PROMOTION OF ELDERLY}

Nowadays, there is a widespread problem of poor status among the elderly population in China. According to statistics, the prevalence of chronic diseases among the elderly over the age of 60 is $51.8 \%$. Physical health is the primary factor affecting the life quality of the elderly [4]. In 2007, sports health promotion project--- "Exercise Is Medicine" jointly launched by ACSM (American College of Sports Medicine) and AMA (The American Medical Association) is an indispensable concept for prevention and treatment of chronic diseases in the elderly. After several years of active promotion, it has attracted the response and participation of many countries (regions) around the world [5]. For elderly health, this study will analyze the effect of exercise intervention on the health of the elderly from the three dimensions of physical health, mental health and social adaptability.

\section{A. Physical Health: Related Research of Prevention and Treatment of Chronic Diseases by Exercise Intervention}

In the past century, with the improvement of economic level, the spectrum of diseases has changed from the high incidence of infectious diseases to the high incidence of chronic diseases. This change has continued to develop in many regions of the world [6]. The increase in the incidence of chronic diseases and medical expenditure is also widespread in the world. The deaths of chronic diseases in China account for more than $80 \%$ of the total deaths. The medical expenditure 
for chronic diseases accounts for $68 \%$ of the total medical expenditure [7]. According to epidemiological surveys, cardiovascular diseases, type II diabetes, and Alzheimer's disease are common chronic diseases in the elderly in China, and they are also important factors affecting the health and life quality of the elderly.

Extensive exercise interventions have shown that the lack of physical activity is the main cause of cardiovascular disease in chronic disease prevention and treatment. Through exercise intervention, the risk of cardiovascular disease can be reduced [8]. The lack of sports lifestyle is one of the reasons lead to type II diabetes. The occurrence of type II diabetes will lead to a decrease in life expectancy and increases the risk of other chronic diseases such as CVD. But its occurrence and development are obviously affected by lifestyle. For example, increasing physical activity and exercise can significantly improve the cardiovascular and endurance of people with diabetes, and can even reduce early mortality and morbidity [9]. The Delphi consensus assessment of global data shows that the global prevalence of $\mathrm{AD}$ is $0.75 \%$, and the incidence increases exponentially with age, from $0.5 \%$ for $60-64$ years old to $7 \%$ for over 90 years old[10]. Domestic and foreign empirical studies have found that the cognitive function of the elderly is malleable, and that proper intervention can effectively protect the cognitive function of the elderly or delay its decline[11] [12] [13]. Observational studies have shown that there is a significant correlation between regular physical activity and cognitive function[14]; a large number of clinical randomized controlled trials also support physical activity interventions to significantly improve cognitive function in healthy elderly people[16] [17]; proper exercise can prevent and delay the progress of $\mathrm{AD}$ as it does with cardiovascular disease[18]. It is of great significance to promote physical activity to prevent the occurrence and development of Alzheimer's disease by exploring the best effective exercise and minimum effective exercise for preventing and alleviating AD.

Through the above studies, it can be seen that exercise intervention has an assistant effect on the prevention and treatment of various chronic diseases of the elderly [18] [19] [20]. Physical activity and exercise can not only bring health benefits in primary prevention, but also bring similar benefits in secondary prevention of diseases. If physical activity and exercise interventions are used after the initial diagnosis of chronic diseases, the harms caused by many diseases can be improved, and even certain diseases (such as type II diabetes) can prevent or delay the progress of the disease [21]. Regular exercise and activity can also help relieve disability and pain associated with these conditions. More importantly, even if you start regular practice later in life, you can enjoy the benefits of physical activity [22]. The purpose of project of "Exercise Is Medicine" launched in 2007 is to promote physical health, prevention of chronic diseases by increasing physical activity, and encourage doctors to regard exercise prescription as part of a chronic disease treatment plan. While exercising intervention, we should also strengthen the education of the elderly to the related medical care and sports knowledge.

\section{B. Mental Health: Related Research of Effect of Mental Health of Elderly by Exercise Intervention}

While paying attention to physical health of elderly, it cannot be ignored of mental health of elderly, either. Mental illness is the biggest factor in the life quality of the elderly, and depression will increase the risk of heart disease [23]. Epidemiological study found that physical activity levels are negatively correlated with negative emotions such as depression and dejection [24]. Kritz-Sliverstein's 3-year follow-up study of people aged 50 to 89 in California found that exercise can effectively reduce negative psychology [25]. Mather's study of the elderly fitness group in the UK concluded that exercise can reduce negative emotions by $30 \%$ compared to the control group [26]. Taylor's study suggests that aerobic exercise can reduce elderly anxiety or physicalpsychological index. Fox, through a 10-week exercise intervention on 40 to 70 -year-old, believes that exercise interventions have significant effects on improving self-esteem and physical self-perception in middle-aged and elderly people [27]. Through the above research, sports cannot only promote the physical health of the individual, but also can promote the individual's mental health.

\section{Social Adaptability: Related Research of Social Adaptability of Elderly by Exercise Intervention}

Social adaptation refers to the process by which an individual interacts with a particular social environment to achieve a coordinated relationship, and the state of this coordinated relationship [28]. Some old age problems are not the problems brought about by the elderly. They are problems for the poorly-adjusted elderly. Domestic research on the participation of the elderly in sports from the social dimension of physical exercise is relatively rare. It is mainly in two aspects of the process of the continuous socialization of the elderly through sports participation, and the role change process of the elderly and sports participation. Qiao Liang discovered that by studying the relationship between urban senior citizens' role change process and sports: "Sports, with its functions of fitness, mentality, and quotient, have a certain role in meeting the role demands of the elderly due to changes in social roles". In the early days of retirement, many people cannot withstand the psychological and physical impact of retirement, resulting in a sense of loss. "The biological and social functions of sports have a positive effect on the regulation of social discomfort caused by the changes in social roles of the elderly" [29]. Sociologist John Wilson believes that in sports participation, social identity is placed above physiological existence. Sports participation gives certain physical characteristics and skills a value, and devalues other aspects, thereby affirming how mind and body are related and some understanding of how the social world and the natural world relate [30]. McAuley's study of 174 elderly people in the United States showed that there are certain social connections in the physical training group, which can improve the life satisfaction of the elderly and reduce loneliness. Group activity in sports is the main motivation and benefit for elder people to participate in group exercise (Finch, 1997)[31]. The role of exercise intervention in relieving the psychological barriers of the elderly and improving social adaptability has attracted more and more attention of scholars. 


\section{CONCLUSION}

From the perspective of domestic and foreign research, exercise intervention has unparalleled advantages in improving the physical and mental health of the elderly. As a whole, the research emphasizes biological evaluation, and there are few economic and sociological achievements, which has great limitations for the formulation of public policies. The existing research results have focused on the descriptive, explanatory, and basic types of physical health promotion in sports; the research on the effect evaluation, risk factors and performance relationship of sports to health promotion is insufficient. This makes the practical results of the research results less practical, less applicable, and poorly-guided. The study and practice of interventions for physical activities of the elderly by the developed countries have entered a more elaborate stage, and the methods of intervention have also become increasingly abundant. In contrast, the exercise interventions and exercise prescriptions of the elderly in China are still in a state of extensiveness. It is not sufficient to educate the health consciousness of the elderly and the basic knowledge of health care. There is arbitrariness in the fitness of old-age and lack of scientific sports guidance.

Therefore, (1) Build an interdisciplinary platform to conduct multidisciplinary research on exercise intervention. The research on exercise intervention and health promotion has gradually become a field of interdisciplinary research from natural sciences to social; (2) actively construct an elderly health assessment system and an empirical study of targeted exercise prescriptions for the elderly; (3) promote the construction of a combination of sports and medicine. Combining the health risks and physical functions of the elderly, we should formulate corresponding interventions that can be implemented to address the general problems in the combination of sports and medicine and the special problems faced by the elderly in health promotion, explore older human medicine combined with effective measures and reasonable scheme to improve the health by the combination of sports and medicine; (4) It is not sufficient to educate the health consciousness of the elderly and the basic knowledge of health care. There is arbitrariness in the fitness of old-age and lack of scientific sports guidance. Exercise intervention is an effective measure to promote the active participation of elderly in physical activities and promote their transition from casual fitness to scientific fitness.

\section{REFERENCES}

[1] Wu Yushao, Dang Junwu. Blue Book on Aging: Report on the development of China's aging industry (2014) [M]. Beijing: Social Science Literature Publishing House, 2014. 吴玉韶, 党俊武. 老龄蓝 皮书: 中国老龄产业发展报告(2014) [M]. 北京: 社科文献出版 社, 2014.

[2] Charles Zastrow. Human Behavior and social environment [M]. Beijing: China Renmin University Press, 2006: 770. 扎斯特罗. 人类行为与社会 环境[M].北京: 中国人民人学出版社，2006: 770。

[3] Wu Cangping. Improve scientific understanding of the quality of life of the elderly [J]. Population research, 2002; 26 (5): 1-5. 邬沧萍. 提高对 老年人生活质量的科学认识 ( $\mathrm{J})$. 人口研究, 2002;26( 5) : 1-5.

[4] Jiang Chuan, 5 Geriatric sociology 6, Science Press, 2007: 36-44. 江 川,5老年社会学 6,科学出版社,2007 年:36-44.
[5] Li Hongjuan, Wang Zhengzhen, Sui Xuemei, etc. Exercise Is Medicine: The best evidence-based practice [J]. Journal of Beijing Sport University, 2013, (6): 43-48. 李红娟, 王正珍, 隋雪梅, 等. 运动是 良医: 最好的循证实践 $[\mathrm{J}]$. 北京体育大学学报, 2013, (6): 4348 。

[6] J. Larry Durstine, Benjamin Gordon, Zhengzhen Wang, et al. Chronic disease and the link to physical activity $[\mathrm{J}]$. JSHS, 2013, 2: 3-11.

[7] Lai Jianqiang, Shi Xiaoming, Wang Limin, etc. Research on prevention and control of chronic diseases [C]. Development report on public health and prevention medicine in2009-2010, Beijing, 2010. 赖建强, 施小明, 王丽敏, 等. 慢性病预防与控制研究 [C] .2009-2010 公共 卫生与预防医学学科发展报告, 北京, 2010 .

[8] TAYLOR. Exercise-based rehabilitation for patients with coronary heart disease: systematic review and meta-analysis of randomized controlled trials[ J] .Am J Med, 2004, 116, (10):682-692.

[9] Wang Juan, Zhang Xianbo, Wang Zhengzhen. The Effect of Regular Exercise on Cardiopulmonary Endurance in Diabetic Patients---Meta analysis [J]. Journal of Beijing Sport University, 2013, 36 (3): 50-56. 王 娟, 张献博, 王正珍. 规律运动对糖尿病患者心肺耐力的影响一二 Meta 分析 $[\mathrm{J}]$. 北京体育大学学报, 2013, 36 (3) : 50-56.

[10] Thiel C, Vogt L, Tesky VA, et al. Cognitive intervention response is related to habitual physical activity in older adults $[\mathrm{J}]$. Aging Clin Exp Res, 2012, 24( 1) : 47-55.

[11] Hill K D, Lo Giudice D, Lautenschlager N T, et al. Effectiveness of balance training exercise in people with mild to moderate severity Alzheimer's disease: protocol for a randomised trial [J]. BMC Geriatr, 2009, 9: 29.

[12] Zhang Jianghua, Kang Jiaxun, Zeng Hui, etc. Comparison of effect of cognitive training and self-massage on cognitive function of the elderly [J]. Journal of Chinese Clinical Psychology, 2011, 19 (03): 394-7. 张江 华, 康佳迅, 曾慧等. 认知训练和自我按摩对老年人认知功能的影响 比较 [J]. 中国临床心理学杂志, 2011, 19(03): 394-7.

[13] Edwards J D, Wadley V, Vance D, et al. The impact of speed of processing training on cognitive and everyday performance [J]. Aging \& mental health, 2005, 9(3):262-71.

[14] Blondell S J. Does physical activity prevent cognitive decline and dementia? A systematic review and meta-analysis of longitudinal studies[J].Public Health Nurs, 2014, 27;14:510.

[15] Colcombe S, Kramer A F. Fitness effects on the cognitive function of older adults: a meta-analytic study [J]. Psychological science, 2003, 14(2): 125-30.

[16] Smith P J, Blumenthal J A, Hoffman B M, etal. Aerobic exercise and neurocognitive performance: a meta-analytic review of randomized controlled trials [J]. Psychosom Med, 2010, 72(3): 239-52.

[17] Wang Zhengzhen, Zhou Yu, Wang Juan. Physical activity and alzheimer's disease [J]. Journal of Beijing Sport University, 2013, 7 (38): 1-6. 王正珍, 周誉, 王娟. 体力活动与阿尔兹海默病 $[\mathrm{J}]$. 北 京体育大学学报, 2013, 7 (38) : 1-6.

[18] Luo Xijuan, Zhang Xianbo, Xu Junhua. Application example of exercise is medicine: American diabetes prevention program and its application [J]. Journal of Beijing Sport University, 2016, (8): 59-65. 罗 爴娟, 张献博, 徐峻华. 运动是良医应用实例: 美国糖尿病预防项 目及其应用 $[\mathrm{J}]$. 北京体育大学学报, 2016，(8): 59-65.

[19] CHASE J A. Physical activity interventions among older adults : a literature review $[\mathrm{J}]$. Res Theory Nurs Pract, 2013, 27(1): 53-80.

[20] Garatachea N, Pareja-Galeano H, Sanchis-Gomar F, et al. Exercise attenuates the major hallmarks of aging. $[\mathrm{J}]$. Rejuvenation Res, 2015, 18(1): $57-89$

[21] Colberg SN, Albright AL, Blissmer BJ, et al. Exercise and Type 2 Diabetes: American College of Sports Medicine and the American Diabetes Association: Joint Position Statement [J] . Med Sci Sports Exerc, 2010, 12 (42) : 2282-2303.

[22] Global strategy for diet, physical activity and health [EB/OL] http://www.who.int/ diet physical activity/zh/.饮食、身体活动与健康 全球攻略 [ EB/OL] http:// www. who. int/ diet physical activity/zh/.

[23] Colcombe S,J Kramera, Fericksonki, e tal. Cardiovas cular fitness, cortical plasticity and aging [ J .Proc Natl Acad Sci,2004, 101(9):33163321. 
[24] Hanssmen P, Koivula N. Physical exercise and psychological wellbeing: a population study in Finland[ J] . Prevention Med, 2000, 30:1725.

[25] Kritz-Sliversteind. Cross-sectional and prospective study of Exercise and depressed mood in the elderly:the Rancho Bernardo study[ J] .Am JE pidemiology, 2001, 153:596-603.

[26] MATHER A S. Effects of exercise on depressive disorder: Randomized controlled trial[ J] .Br J Psychiatry, 2002, 180:411-415.

[27] FOX K R. The effects of exercise on self-perceptions and self-esteem, Physical activity and Psychology Wel-being[ M] . London:Routledge, 2000:88-117.

[28] Chen Bo, Study on social adaption of urban elderly under the background of population aging [J] The Social sciences, 2008 (6): 89-9. 陈勃, 人口老龄化背景下城市老年人的社会适应问题研究 [J]社会科 学,2008 (6):89-9.

[29] Qiao Liang. The process of social role change and sports in urban elderly[J]. China Sport Science and Technology, 2002, 38 (3): 38-42. 乔 梁.城市老年人社会角色变迁过程与体育[J].中国体育科技, 2002, 38(3):38-42.

[30] Jay J Coakley. Sports Sociology - Issues and Controversies (The 6th Edition) $[\mathrm{M}]$. Translated by Guan Bing, et al, Tsinghua University Press, 2003: 14. Jay J Coakley.体育社会学——议题与争议(第六 版)[M].管兵等译.清华大学出版社, 2003:14.

[31] Finch H. Physical activity at our age: Qualitative Research among People over the Age of 50[ M] .London: Health education authority, 1997. 